\title{
OXYGEN REDUCTION ON PYROLYSED CARBON-SUPPORTED TRANSITION METAL CHELATES
}

\author{
A. VAN DER PUTTEN, A. ELZING, W. VISSCHER and E. BARENDRECHT \\ Laboratory for Electrochemistry, Department of Chemical Technology, Eindhoven Unuersity of Technology, \\ P.O. Box 513, $5600 \mathrm{MB}$ Eindhoven (The Netherlands)
}

(Recelved 16th September 1985; in revised form 23rd December 1985)

\begin{abstract}
A review is given of the pyrolysis behaviour of carbon-supported transition metal chelates and the developed theories explaining the increased activity and stability towards oxygen reduction. Additional measurements with a new carbon-modified rotating ring-disc electrode show that the central metal ion- $\mathrm{N}_{4}$ unit remains the active site after pyrolysis. The selectivity is increased after pyrolysis since relatively less $\mathrm{H}_{2} \mathrm{O}_{2}$ is detected at the ring. The number of available active sites is an important parameter for the resulting activity. During the heat treatment, different processes take place: migration of the chelates over the carbon support, increasing the number of available active sites; reaction of the outer fringes of the organic skeleton retaining the metal ion- $\mathrm{N}_{4}$ unit; and degradation of the catalyst with loss of activity. The condition of the pyrolysed catalyst and its corresponding activity are determined by the relative rate of these processes at the given pyrolysis temperature.
\end{abstract}

\section{INTRODUCTION}

Transition metal chelates have been studied for $\mathrm{O}_{2}$ reduction, both in alkaline and in acid solution. Usually, the chelate is dispersed onto a carbon support and applied as a gas diffusion electrode. It has already been established by Jahnke et al. [1] in 1973 that heat treatment in an inert atmosphere (pyrolysis) favourably affects the activity and stability towards $\mathrm{O}_{2}$ reduction. A survey of the literature published so far [2-19] shows that the results obtained can hardly be compared with each other, owing to great differences in the experimental conditions. of which the most important are:

(i) the chelate under consideration;

(ii) the pyrolysis temperature;

(iii) the carbon support and the method of chelate dispersion on this carbon;

(iv) the electrolyte in which the $\mathrm{O}_{2}$ reduction is measured.

Most of the work has been performed on the tetraphenyl-porphyrins (TPP), tetramethoxyphenyl-porphyrins (TMPP), dibenzotetraazaannulenes (TAA) and phthalocyanines $(\mathrm{Pc})$ of $\mathrm{Fe}$ and $\mathrm{Co}$; however, metal-free compounds have also been used to study the effect of the central metal atom. 
TABLE 1

Overview of the chelates investıgated and corresponding pyrolysis temperatures

\begin{tabular}{lll}
\hline Chelate & $T_{\mathrm{p}} /{ }^{\circ} \mathrm{C}$ & Reference \\
\hline $\mathrm{H}_{2}$, CoTMPP & 800 & 2 \\
Fe. CoTPP $/ \mathrm{Fe}$. CoPc & $600-800$ & 3 \\
CoTPP & $500-700$ & 4 \\
CoTPP/CoTMPP/CoTBP & $800-900$ & 5 \\
CoTMPP & $300-1200$ & 6 \\
$\mathrm{H}_{2}$, CoTMPP & 830 & 7 \\
CoTPP & 700 & 8 \\
CoTMPP & $800-900$ & 9 \\
CoTAA & 950 & 10 \\
$\mathrm{H}_{2}$, CoTAA & $300-1200$ & 11 \\
$\mathrm{H}_{2}$, CoTMPP & 830 & 12 \\
$\mathrm{H}_{2}$, CoTAA & 650 & 13 \\
CoTMPP & $300-1200$ & 14 \\
Co. FeTMPP & 700,800 & 15 \\
$\mathrm{H}_{2}$, CoPc/FcTPP & 950 & 16 \\
FeTPP.Cl & $200-1000$ & 17 \\
CoTAA/CoTAA.Br & 500 & 18 \\
CoTAA & 700 & 19 \\
\hline
\end{tabular}

In addition, the pyrolysis conditions differ widely. Most authors carry out the pyrolysis in an inert atmosphere $\left(\mathrm{Ar}, \mathrm{N}_{2}\right)$ at different temperatures. An overview of the chelates investigated and corresponding pyrolysis temperatures can be found in Table 1. It is striking that in most cases no temperature programme is given, even though this programme can influence the ultimate results.

Another important parameter is the carbon support and the applied impregnation method. Properties such as the chemical nature of the carbon, pore size and pore size distribution, specific surface area, etc. determine. together with the catalyst loading. whether the catalyst is present as a (sub)monolayer coverage or in the form of aggregates. This is also influenced by the preparation method and the properties of the chelate itself: mechanical mixing, for instance [9], will give aggregates; precipitation from a solution gives a more uniform coverage. A number of different carbons and some of their properties are presented in Table 2.

TABLE 2

Some properties of frequently used carbon supports

\begin{tabular}{llcll}
\hline Carbon & Chemical nature & $\begin{array}{l}S_{\mathrm{BET}} \\
/ \mathrm{m}^{2} \mathrm{~g}^{-1}\end{array}$ & $\begin{array}{l}\text { Catalyst } \\
\text { loading } \\
\text { (weight \%) }\end{array}$ & Authors \\
\hline Norit BRX & active carbon & 1800 & 20 & Van Veen et al. [3] \\
P33 & actıve carbon & 1020 & $10-20$ & Wiesener and co-workers [6,7,11-14] \\
Vulcan XC72 & acetylene black & 250 & 5 & Yeager and co-workers [9] \\
\hline
\end{tabular}


Finally, the results are influenced by the electrolyte in which the $\mathrm{O}_{2}$ reduction is studied. Most authors use $\mathrm{H}_{2} \mathrm{SO}_{4}$ at room temperature; however, $\mathrm{H}_{3} \mathrm{PO}_{4}[2,10]$, $\mathrm{NaCl}$ [16], $\mathrm{NaOH}$ [9] and $\mathrm{KOH}$ [15] are also used. In our opinion, results obtained in alkaline solution are not so revealing since the reduction of $\mathrm{O}_{2}$ to $\mathrm{H}_{2} \mathrm{O}_{2}$ in this electrolyte is quasi-reversible; only slight differences in activity between the different chelates exist and even carbon itself has a high activity towards oxygen reduction. Therefore, the results are determined more by the physical texture of the catalyst/carbon support than by the chemical composition of the catalyst itself.

Virtually all electrochemical measurements have been performed on gas diffusion electrodes. With this type of electrode, only $i-E$ curves can be measured, as a function of time. Major drawbacks are that no information about the selectivity can be obtained and that the transport of $\mathrm{O}_{2}$ is ill-defined. The fraction of the electrode surface which is active for the $\mathrm{O}_{2}$ reduction is determined mainly by the wetting of the carbon. In general, impregnation of the support with a catalyst and the pyrolysis will change the degree of wetting and thus also the electrochemical behaviour.

Some results with rotating ring-pasted disc electrodes (RRDE) have also been published [5,9,17]. Bagotskii et al. [5] and Scherson et al. [9] used Teflon to attach the carbon to the disc, retaining the wetting problem; Ikeda et al. [17] applied FeTPP.Cl onto glassy carbon, but in the absence of a porous carbon support. For chemical and physical characterization of the carbon-supported chelates before and after pyrolysis, a spectrum of different techniques was used, such as DTA/TG, chemical analysis, conductivity, magnetic susceptibility, BET surface determination, and spectroscopy such as X-ray, IR, TEM, MS, ESR, XPS, ESCA and EXAFS.

Summarizing, we must conclude that each chelate has its own characteristic pyrolysis behaviour which depends on the carbon support, the temperature program and the pyrolysis temperature. However, there is no unambiguous opinion as to why pyrolysis has a beneficial effect on the activity.

\section{Developed theories for activity enhancement}

It is generally agreed that the improved stability is caused by the reaction of the chelate with the carbon support. The most reactive parts of the molecule are then no longer susceptible to irreversible oxidation due to the formation of hydrogen peroxide. Moreover, the pyrolysed catalysts are better $\mathrm{H}_{2} \mathrm{O}_{2}$ decomposers, resulting in a lower $\mathrm{H}_{2} \mathrm{O}_{2}$ concentration in the pores of the catalyst.

With regard to the improvement in activity, different opinions are presented. An important factor here is the role of the central metal atom. With unpyrolysed catalysts the central metal ion is the active site. The question is whether this is also the case after pyrolysis. According to Wiesener and co-workers [6,7,11-14], the cobalt is no longer the active site after pyrolysis. During pyrolysis a new catalyst is formed, consisting of nitrogen and carbon. The cobalt acts as a promotor for these pyrolysis reactions. The most convincing evidence for this theory should be the measured activity of $\mathrm{H}_{2}$ TAA and CoTAA as a function of pyrolysis temperature. In both cases the same bell-shaped curve was obtained [11]. shifted only with respect to 
the temperature. Measurements of the $\mathrm{H}_{2} \mathrm{O}_{2}$ decomposition and the BET surface showed the same behaviour, indicating that both with $\mathrm{H}_{2}$ TAA and with CoTAA the same catalyst is formed, but at different temperatures. The presence of cobalt accelerates the pyrolysis reactions so that the maximum is already obtained at lower temperatures. The authors reported the same behaviour with catalysts in which $\mathrm{Co}$ and $\mathrm{H}_{2}$ TAA were added separately: after pyrolysis, the same activity as that with pyrolysed CoTAA was obtained.

This theory is contradicted by Yeager and co-workers [9]. They also conclude that cobalt accelerates the pyrolysis reactions, but in their opinion the increased activity is not caused by the pyrolysis product of the organic skeleton, i.e. a nitrogen-carbon compound. Their conclusion is based on the result that pyrolysed $\mathrm{H}_{2}$ TMPP $\left(800^{\circ} \mathrm{C}\right)$ did not show an improved activity. Unfortunately these authors did not measure the activity at different pyrolysis temperatures; it could be that for the improvement of $\mathrm{H}_{2}$ TMPP a higher temperature is necessary. Mössbauer spectroscopy of pyrolysed CoTMPP showed the presence of cobalt oxide. In their opinion, some kind of cobalt species is responsible for the improved activity, but their explanation remains a bit vague. In their view, the results of Wiesener et al. with $\mathrm{H}_{2}$ TAA are a consequence of the presence of impurities in the P33 carbon. However, according to Gruenig [20], extensive purification of the carbon had no effect.

A third explanation was offered by Van Veen et al. [3]. based on the concept of redox catalysis. Their results should prove that the chelate indeed reacts with the carbon support; however, the $\mathrm{MeN}_{4}$ units remain intact $\left(T \leqslant 800^{\circ} \mathrm{C}\right)$ according to EXAFS measurements. In their view, two kinds of catalyst can be discerned: metal chelates for which the redox potential is too positive $(\mathrm{Co})$ or too negative (Fe). With Co complexes, saturation of the organic skeleton due to pyrolysis leads to an increased electron density on the metal ion, resulting in a more negative redox potential. With Fe complexes also, a bond is formed between the Fe and the substrate, lowering the electron density on the metal ion; the net effect of these processes shifts the redox potential towards positive values. Therefore, the activity of both $\mathrm{Co}$ and $\mathrm{Fe}$ complexes increases after pyrolysis, irrespective of whether the redox potential at room temperature is too positive or too negative. This explanation seems very unlikely, since the $\pi$-system of the organic skeleton will become larger due to polymerization with the support. Electrons that took part in the Co $\mathrm{N}$ bond will become more delocalized, resulting in a weakened ligand field. The Co complex will change from a low-spin into a high-spin complex with a higher electron density on the $3 d_{z}^{2}$ orbital, facilitating $\mathrm{O}_{2}$ adsorption [4].

Summarizing, we can state that the different opinions regarding the increased catalytic activity after pyrolysis are not necessarily caused by conflicting experimental results. A meaningful comparison between different chelates can be made only if the chelates are compared over the whole temperature range $300-1200^{\circ} \mathrm{C}$. Comparison at only one temperature has no meaning; some chelates would not have reacted at all while others would already have totally decomposed. Another requirement is a good discrimination between physical and chemical effects. With gas diffusion 
electrodes this is impossible since modification of the carbon support influences the catalytic, transport and wetting properties. It is therefore risky to draw conclusions about what happens with the transition metal macrocycles themselves. In this paper the activity and selectivity of some chelates will be compared as a function of the pyrolysis temperature. Furthermore, the effect of the carbon support will be investigated.

As stated above, the transport of $\mathrm{O}_{2}$ in gas diffusion electrodes is ill-defined. Moreover, the actual surface area where the electrochemical processes take place is not known exactly and depends on the wetting properties of the catalyst system. Therefore, a different type of electrode was used, developed in our laboratory [21].

\section{EXPERIMENTAL}

The (modified) carbon particles are attached to the disc of a RRDE via incorporation in a conducting polypyrrole film. With this more sophisticated hydrodynamic technique, the transport of $\mathrm{O}_{2}$ to the electrode is well-defined; at the ring electrode the $\mathrm{H}_{2} \mathrm{O}_{2}$ production can be monitored, and so the selectivity can be determined. Moreover, since the entire pore system can be filled with electrolyte, and the $\mathrm{O}_{2}$ is transported to the catalyst via the liquid phase, the wetting problem does not occur. This enables a better distinction between physical and chemical parameters.

Experiments were conducted with 20 weight $\%, \mathrm{H}_{2^{-}}$, Co- and FePc (Eastman Kodak), and $\mathrm{H}_{2}$ - and CoTAA, kindly provided by Professor Wiesener (Technische Universität, Dresden). Two supports were used: Norit BRX and P33, the latter also provided by Professor Wiesener. Impregnation of the carbon was realized by dissolving $10 \mathrm{mg}$ of the corresponding chelate in $20 \mathrm{ml}$ of tetrahydrofuran (THF). adding $40 \mathrm{mg}$ of carbon support, followed by refluxing and stirring for $30 \mathrm{~min}$. Thereafter, the catalysts were pyrolysed in $\mathrm{N}_{2}$ at temperatures ranging from 400 to $1200^{\circ} \mathrm{C}$. In general, the catalysts were heated to the desired pyrolysis temperature in $1 \mathrm{~h}$. maintained at this temperature for $4 \mathrm{~h}$ and cooled slowly to room temperature. In a few cases, the pyrolysis was done in Ar. The pyrolysed catalysts were ground in an agate mortar and $0.25 \mathrm{mg}$ was attached to the gold disc $\left(0.5 \mathrm{~cm}^{2}\right)$ of a RRDE (Au disc, Pt ring, $N=0.23$ ) via incorporation in a polypyrrole film according to the described procedure [21]. The electrochemical experiments were conducted in a standard three-compartment electrochemical cell, filled with $150 \mathrm{ml}$ of $\mathrm{O}_{2}$-saturated $0.5 \mathrm{M} \mathrm{H}_{2} \mathrm{SO}_{4}$. The $\mathrm{O}_{2}$ reduction was measured at $20^{\circ} \mathrm{C}$ by scanning the potential from 1000 to $200 \mathrm{mV}$ (vs. RHE) with $10 \mathrm{mV} \mathrm{s}^{-1}$, at a rotation frequency of $9 \mathrm{~s}^{-1}$. The disc current was corrected for the high capacitive polypyrrole background current [21].

Since the number of active sites is perhaps the most important parameter determining the reduction capability, Norit BRX electrodes were prepared containing 1-50 weight $\% \mathrm{CoPc}$. Finally, to allow a reasonable comparison, the "intrinsic catalytic activity" (turnover number) of both CoPc and CoTAA, adsorbed on a pyrolytic graphite ( $\mathrm{Cp}) \operatorname{disc}\left(S=0.5 \mathrm{~cm}^{2} ; N=0.27\right)$ at monolayer coverage, was measured. 


\section{RESULTS}

In Figs. 1 and 2, the results in $0.5 \mathrm{M} \mathrm{H}_{2} \mathrm{SO}_{4}$ for $20 \% \mathrm{CoPc}$. FePc and $\mathrm{H}_{2} \mathrm{Pc}$ supported on Norit BRX are depicted as a function of the pyrolysis temperature. As reported previously [21], the pure diffusion-limited currents $\left(750 \mu \mathrm{A}\right.$ at $9 \mathrm{~s}^{-1}$ for $\mathrm{O}_{2} \rightarrow \mathrm{H}_{2} \mathrm{O}_{2}$ ) are not reached since a fraction of the electrode is not covered with carbon particles. The activity of $\mathrm{CoPc}$ increases up to a treatment temperature of $600^{\circ} \mathrm{C}$; at higher temperatures, however, degradation of the catalyst occurs with loss of performance. This activity increase is accompanied by a decrease in the amount of peroxide formed, caused by electrochemical reduction or chemical decomposition of the $\mathrm{H}_{2} \mathrm{O}_{2}$. The activity of $\mathrm{FePc}$ increases slightly up to $600^{\circ} \mathrm{C}$; at higher temperatures, very rapid degradation occurs, so FePc seems to be less resistant against heat treatment than CoPc.

Another conclusion that can be drawn from Fig. 2 is that the activity of $\mathrm{H}_{2} \mathrm{Pc}$ does not increase after pyrolysis, not even at high temperature. This is in contrast with the results of Wiesener and co-workers, who claim that with $\mathrm{H}_{2} \mathrm{TAA}$ pyrolysed at $950^{\circ} \mathrm{C}$, the same catalyst is formed as with CoTAA at $650^{\circ} \mathrm{C}$. To investigate this discrepancy, catalysts were prepared ( 20 weight $\%$ ) of CoTAA, CoPc, $\mathrm{H}_{2}$ TAA and
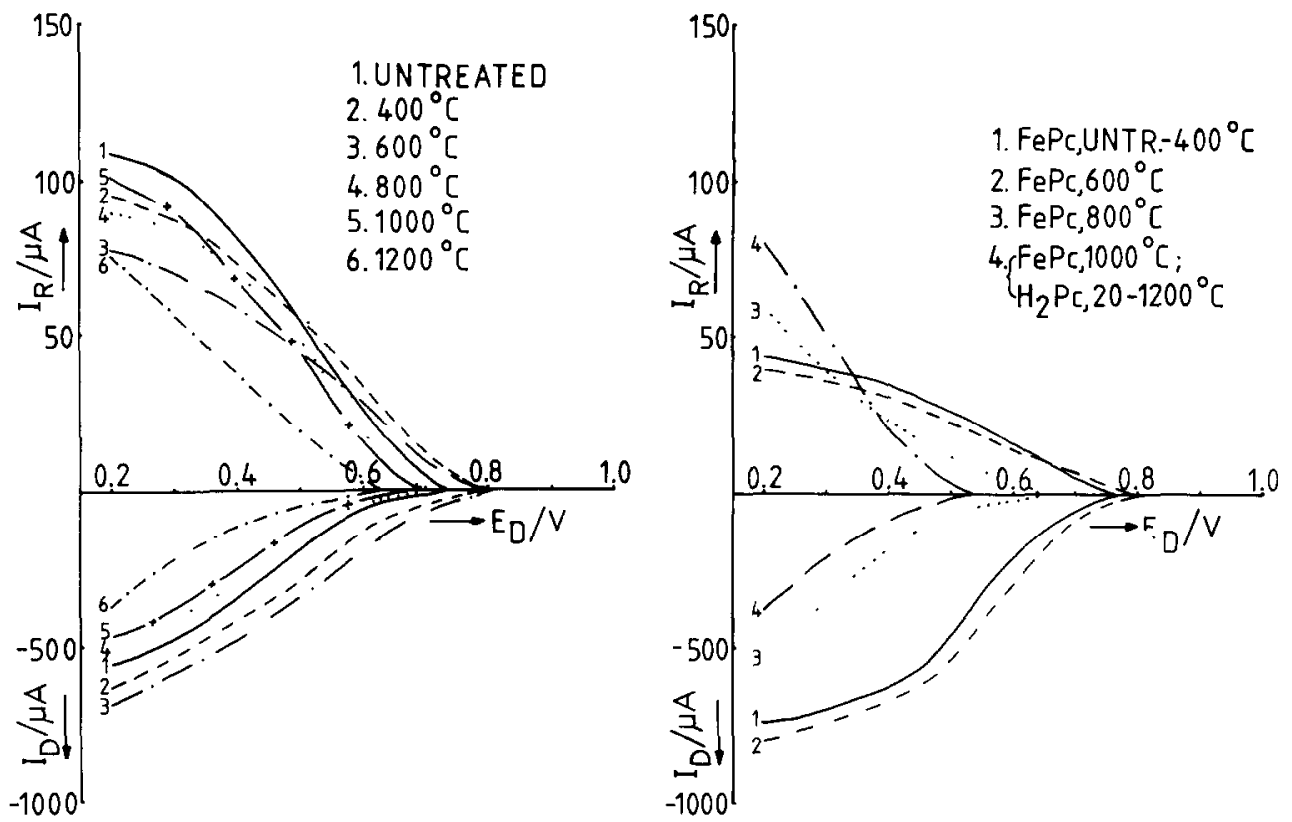

Fig. $1 . \mathrm{O}_{2}$ reduction in $0.5 \mathrm{M} \mathrm{H}_{2} \mathrm{SO}_{4}$ at $f=9 \mathrm{~s}^{-1}$ on $20 \% \mathrm{CoPc} / \mathrm{BRX}$ as a function of pyrolysis temperature.

Fig. $2 \mathrm{O}_{2}$ reduction in $0.5 \mathrm{M} \mathrm{H}_{2} \mathrm{SO}_{4}$ at $f=9 \mathrm{~s}^{-1}$ on $20 \% \mathrm{FePc} / \mathrm{BRX}$ and $20 \% \mathrm{H}_{2} \mathrm{Pc} / \mathrm{BRX}$ as a function of pyrolysis temperature. 
$\mathrm{H}_{2} \mathrm{Pc}$, both on P33 carbon and Norit BRX. The cobalt-containing catalysts were pyrolysed at $650^{\circ} \mathrm{C}$, the metal-free ones at $950^{\circ} \mathrm{C}$. The pyrolysis was carried out both in $\mathrm{N}_{2}$ and in $\mathrm{Ar}$, but no differences were observed within the error of the measurement. The results for CoTAA are presented in Fig. 3. It is clear that unpyrolysed CoTAA is already very active; in contrast to CoPc, the reduction also proceeds to water in the potential range studied. Both activity and selectivity are influenced by the carbon support: the peroxide elimination especially is improved with Norit BRX as compared to P33. It is surprising that the disc current decreases after pyrolysis, probably because of a decrease in the number of active sites. The ring current, however, indicates that the selectivity has increased. The behaviour of $\mathrm{CoPc}$ on these carbons is quite different (Fig. 4). On both supports, disc and ring currents increase and decrease, respectively, showing an increased activity and selectivity after pyrolysis. The results with $\mathrm{H}_{2}$ TAA (Fig. 5) show that although a slight increase in activity has occurred, by no means the same calalyst is formed as with pyrolysed CoTAA.

The better performance of carbon-supported CoTAA in comparison with CoPc can be attributed to a higher intrinsic catalytic activity of CoTAA. This is illustrated
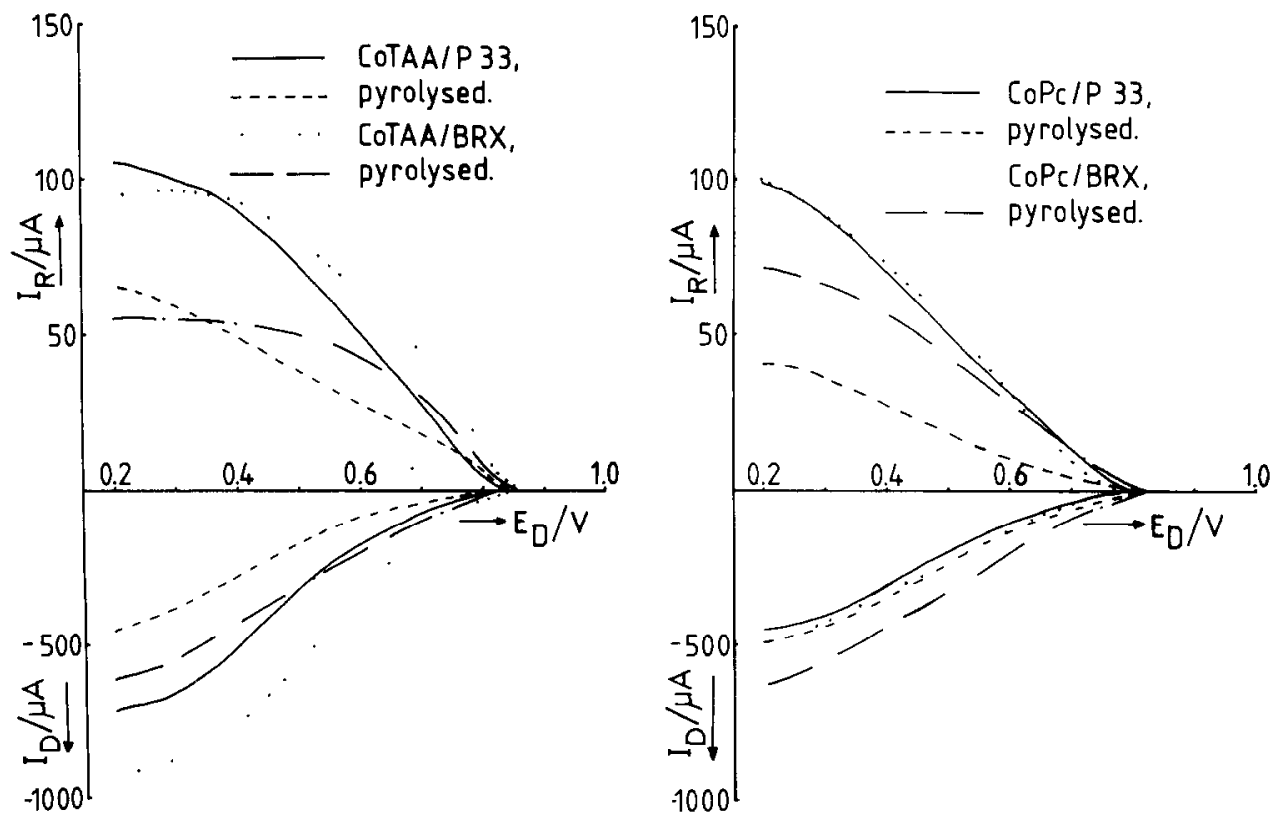

Fig. 3. $\mathrm{O}_{2}$ reduction in $0.5 \mathrm{MH}_{2} \mathrm{SO}_{4}$ at $f=9 \mathrm{~s}^{-1}$ on $20 \%$ CoTAA/P33 and $20 \%$ CoTAA/BRX, both unpyrolysed and pyrolysed at $650^{\circ} \mathrm{C}$

Fig. 4. $\mathrm{O}_{2}$ reduction in $0.5 \mathrm{M} \mathrm{H}_{2} \mathrm{SO}_{4}$ at $f=9 \mathrm{~s}^{-1}$ on $20 \% \mathrm{CoPc} / \mathrm{P} 33$ and $20 \% \mathrm{CoPc} / \mathrm{BRX}$. both unpyrolysed and pyrolysed at $650^{\circ} \mathrm{C}$. 

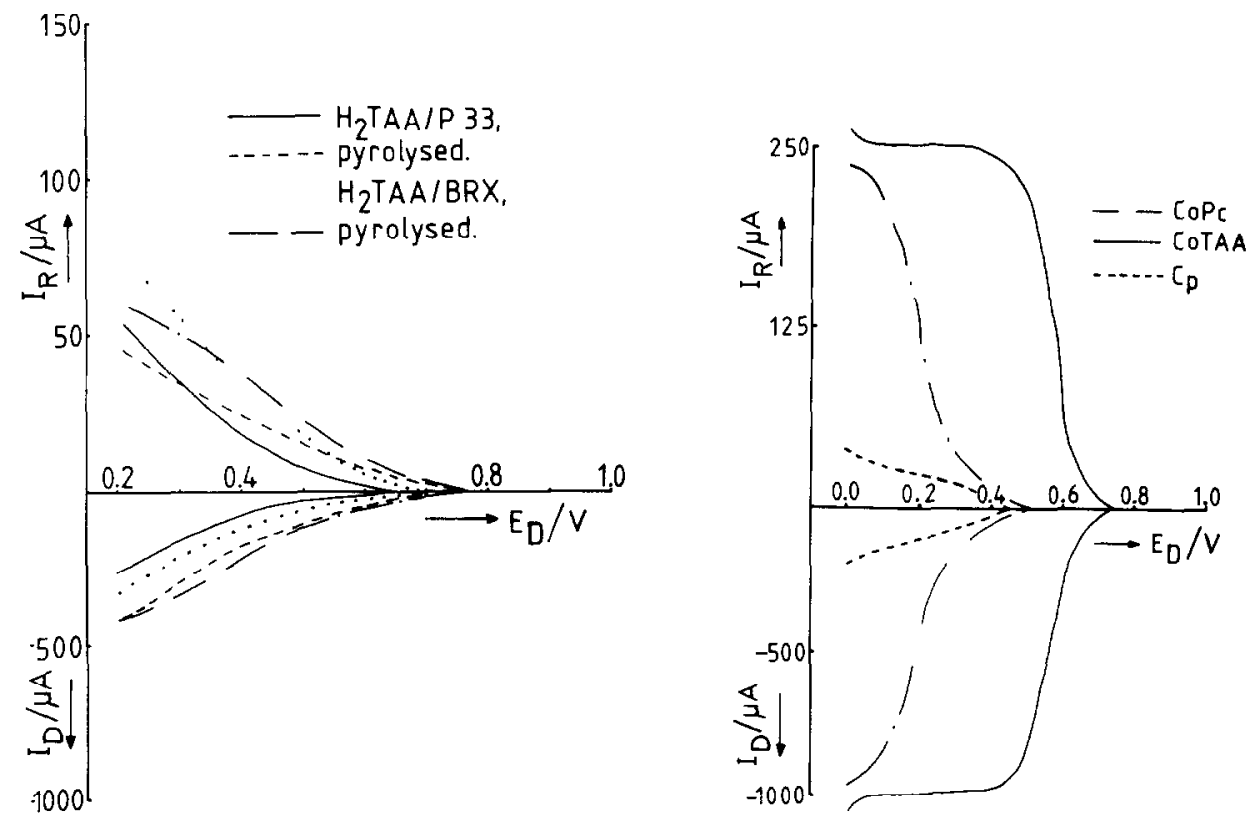

Fig 5. $\mathrm{O}_{2}$ reduction in $0.5 \mathrm{MH}_{2} \mathrm{SO}_{4}$ at $f=9 \mathrm{~s}^{-1}$ on $20 \% \mathrm{H}_{2} \mathrm{TAA} / \mathrm{P} 33$ and $20 \% \mathrm{H}_{2} \mathrm{TAA} / \mathrm{BRX}$. both unpyrolysed and pyrolysed at $950^{\circ} \mathrm{C}$.

Fig. 6. $\mathrm{O}_{2}$ reduction in $0.5 \mathrm{M} \mathrm{H}_{2} \mathrm{SO}_{4}$ at $f=16 \mathrm{~s}^{-1}$ on $\mathrm{CoPc}$ and CoTAA, adsorbed at monolayer coverage on pyrolytic graphite $\mathrm{Cp}$.

in Fig. 6. The reduction of $\mathrm{O}_{2}$ was measured in $0.5 \mathrm{M} \mathrm{H}_{2} \mathrm{SO}_{1}$ at CoTAA and CoPc, adsorbed as a monolayer on pyrolytic graphite $(\mathrm{Cp})$. The electrodes were prepared by dipping a freshly polished $\mathrm{Cp}$ electrode in a $10^{-3} \mathrm{M}$ pyridine solution of CoTAA and $\mathrm{CoPc}$. respectively. Electrochemical characterization in oxygen-free $1 M \mathrm{KOH}$ [22] yielded redox peaks corresponding to $2.3 \times 10^{-10}$ and $2.6 \times 10^{-10} \mathrm{~mol} \mathrm{~cm}^{-2}$ for CoTAA and CoPc. respectively. The $E_{1 / 2}$ for the $\mathrm{O}_{2}$ reduction is about $370 \mathrm{mV}$ more positive for CoTAA. Both at CoTAA and at CoPc, the reduction proceeds to $\mathrm{H}_{2} \mathrm{O}_{2}$ exclusively, since $N=0.27$. In this case, pure diffusion-limited currents ( 1000 $\mu \mathrm{A}$ at $16 \mathrm{~s}^{-1}$ for $\mathrm{O}_{2} \rightarrow \mathrm{H}_{2} \mathrm{O}_{2}$ ) are obtained since the entire surface is electrochem1cally active. Figure 6 proves again that results with different chelates, supported on different carbons, are difficult to compare with each other owing to differences in the intrinsic catalytic activities themselves.

The effect of the total amount of catalyst present on the disc on the disc and ring currents obtained was investigated by varying the weight $\% \mathrm{CoPc}$ on Norit BRX from 1 to 50. The results (Fig. 7) show that increasing the number of sites shifts the $E_{1 / 2}$ towards positive values. In fact, this behaviour looks like the observed improvement of $\mathrm{CoPc} / \mathrm{BRX}$ due to pyrolysis, i.e. the increase in the disc current after pyrolysis can be caused by an increment in the number of available active 


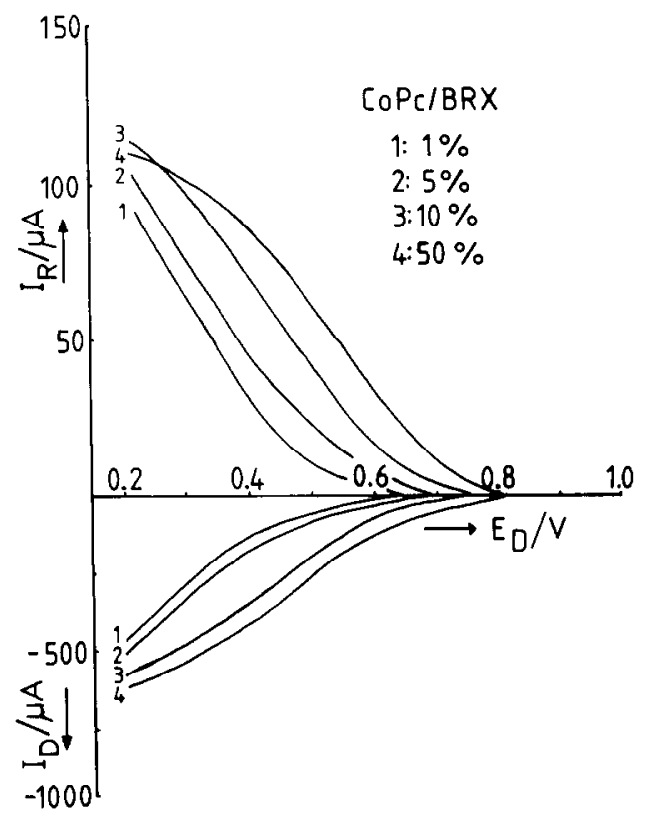

Fig. 7. $\mathrm{O}_{2}$ reduction in $0.5 \mathrm{MH}_{2} \mathrm{SO}_{4}$ at $f=9 \mathrm{~s}^{-1}$ on $\mathrm{CoPc} / \mathrm{BRX}$ as a function of the CoPc loading (werght \%).

sites. Another phenomenon is that at high loadings the peroxide elimination is accelerated. From Fig. 6 it can be seen that $\mathrm{CoPc}$ and CoTAA, adsorbed on a monolayer level, do not reduce or decompose $\mathrm{H}_{2} \mathrm{O}_{2}$; however, porous systems with high loadings in good electrical contact are indeed able to accomplish this in the potential range studied.

\section{DISCUSSION}

A literature survey and our results indicate that the activity and the pyrolysis behaviour of carbon-supported transition metal chelates is determined by various factors, such as the chelate under consideration, the texture of the carbon support. the dispersion of the catalyst over the support, the kinetics of the pyrolysis reactions, etc. These factors are both of chemical and physical nature. Relevant conclusions about what happens to the catalyst itself can only be drawn if this distinction can be made. Gas diffusion electrodes are not suited for this purpose: the modified RRDE electrode described in this paper is better in this respect: however, the distinction remains difficult. Nevertheless, some general conclusions can be drawn: The central metal is the active site with unpyrolysed catalysts. This is also the case after pyrolysis since the activity of metal-free chelates hardly increases. Our measurements do not confirm the theory of Wiesener and co-workers: at 
$950^{\circ} \mathrm{C}$, pyrolysed $\mathrm{H}_{2} \mathrm{TAA} / \mathrm{P} 33$ did by no means approach the activity of CoTAA/P33 pyrolysed at $650^{\circ} \mathrm{C}$. All pyrolysed catalysts show an increased peroxide elimination; the changes in activity are more difficult to interpret. During the heat treatment, the following processes can take place:

(i) migration of chelates over the carbon surface [23];

(ii) reaction of the outer fringes of the organic skeleton of the chelate with the support, the central metal- $\mathrm{N}_{4}$ unit remaining intact;

(iii) decomposition of the chelate giving $\beta$-Co or cobalt oxides after contact with air. It is unlikely that these "metal-only" species are the new active sites in acid medium since the pyrolysis of carbon, impregnated with cobalt acetate only, does not lead to an enhanced activity.

All these processes have their own kinetics with their own temperature dependence, and the condition of the pyrolysed catalyst is determined by the relative rate of these processes at the given pyrolysis temperature. At high temperature the decomposition dominates, but this decomposition also seems to occur at lower temperatures where the pyrolysis still has a beneficial effect on the activity. On the basis of the arguments described above, we arrive at the following model: Starting with the unmodified carbon support, a large available surface area is present which, however, has a very low activity towards $\mathrm{O}_{2}$ reduction. Impregnation with chelates has two opposing effects regarding the activity. The $\mathrm{O}_{2}$ reduction is enhanced owing to the presence of the catalyst, but in addition the pore system is partially blocked, resulting in a lower effective surface area. To what extent the pores are blocked depends on the catalyst loading, the size of the molecules themselves and on the impregnation method, i.e. whether the catalyst is already dispersed or present in the form of aggregates. With increasing pyrolysis temperature, diffusion of the chelates and (partial) decomposition start to occur. These processes again have an opposing effect on the activity: a more random dispersion will increase the number of available active sites; moreover, the accessibility of the pore system as compared to the unmodified carbon is restored. Of course, decomposition decreases the activity. The actual pyrolysis temperature determines which effect predominates. If the temperature is too high. decomposition overrides the improved dispersion: the number of active sites even decreases compared to the unpyrolysed material.

Another effect is the reaction of the outer fringes of the organic skeleton with the support. As long as the $\mathrm{Me}-\mathrm{N}_{4}$ unit remains intact, the activity is preserved: by this reaction, the improved dispersion obtained during the heat treatment is retained after cooling to room temperature. This reaction is probably responsible for the improved peroxide elimination, lowering the $\mathrm{H}_{2} \mathrm{O}_{2}$ concentration in the pore system. Also, since the most reactive parts of the molecule have already reacted, the catalyst is less sensitive to irreversible oxidation caused by (peroxide) intermediates formed during the $\mathrm{O}_{2}$ reduction. With this model, the observed results can be explained: pyrolysis of FePc virtually does not enhance the activity since the stability of FePc is relatively low: degradation already occurs at a relatively low temperature. $\mathrm{CoPc}$ is better in this respect, leading to an increased activity. $\mathrm{H}_{2} \mathrm{Pc}$ remains inactive since a transition metal ion is essential for the catalysis. The high activity of CoTAA 
compared to $\mathrm{CoPc}$ is due to the higher intrinsic activity of CoTAA itself and, to a lesser extent, to the fact that with the same loading in weight \% more catalyst molecules are present in the case of CoTAA because of the difference in molecular weight (345 vs. 572). Moreover, we expect CoTAA to yield better dispersions than $\mathrm{CoPc}$ since the molecule is much smaller, penetrating more easily in the pore system of the support. This also provides an explanation for the decrease in the disc current after pyrolysis of CoTAA. Already at room temperature an excellent dispersion is obtained: pyrolysis does not improve this dispersion. Some molecules react with the support, increasing the peroxide elimination; others decompose and lose their activity. The net effect is a decrease in disc current accompanied by an increase in selectivity. Perhaps some molecules sublime from the carbon support owing to the relatively high vapour pressure of CoTAA compared to CoPc. This possibility was checked by performing the pyrolysis in a small sealed quartz tube filled with $\mathrm{N}_{2}$ at atmospheric pressure. Sublimation should, if not prevented at all, at least be reduced.

However, these experiments gave virtually the same results, for both CoTAA and $\mathrm{H}_{2}$ TAA on P33 carbon, as when the pyrolysis was carried out in a flowing $\mathrm{N}_{2}$ stream. It should be noted also that the measurements of Gruenig et al. [20], showing the change in BET surface area as a function of the pyrolysis temperature, are inexplicable if sublimation is occurring. After pyrolysis, the original BET surface area of the P33 carbon is restored. This happens at a lower pyrolysis temperature for CoTAA than for the more volatile $\mathrm{H}_{2}$ TAA. If sublimation were occurring. the reverse behaviour would have been observed.

The improved performance of pyrolysed CoTAA measured at gas diffusion electrodes is more probably caused by improved wetting characteristics, enabling a better utilization of the available surface area.

\section{REFERENCES}

1 H. Jahnke. M. Schönborn and G Zımmerman in H. Kropf and F. Steınhach (Eds.). Katalyse an Phthalocyanınen, Georg Theme, Stuttgart, 1973, p. 71.

2 R. Holze. D. Scherson. D. Tryk, S. Gupta and E. Yeager, 35th I.S.E Meeting. Berkeley. CA. 1984. Abstr. p. 399.

3 J.A.R. van Veen, J.F. van Baar and K.J. Kroese. J. Chem Soc., Faraday Trans. 1.77 (1981) 2827.

4 K. Okabayashi, O. Ikeda and H. Tamura, Chem. Lett., (1982) 1659.

5 V.S. Bagotski. M.R. Tarasevich, O.A. Levina, K.A. Radyushkina and S.I. Andruseva. Dokl. Akad Nauk SSSR, 233 (1977) 889.

6 A. Fuhrmann, K. Wiesener, I. Mliev, S. Gamburtsev and A. Kaisheva, J. Power Sources, 6 (1981) 69.

7 A. Kaisheva, S. Gamburtsev and I. Iliev, Elektrokhımıy. 18 (1982) 139.

8 R.W. Joyner, J.A.R. van Veen and W.II.M. Sachtler, J. Chem. Soc., Faraday Trans. 1.78 (1982) 1021.

9 D.A. Scherson, S.L. Gupta, C. Fierro, E.B. Yeager, M E. Kordesch, J. Eldridge, R.W. Hoffman and J Blue. Electrochım. Acta, 28 (1983) 1205.

10 A Abelleira, F. Kullk and F. Walsh in ref. 2, p. 396.

11 G. Gruenı, K. Wiesener, S. Gamburzev, I. Iliev and A Kaisheva. J. Electroanal. Chem.. 159 (1983) 155.

12 S. Gamburtsev, I. Iliev and A. Karsheva, Elektrokhimiya, 19 (1983) 1261

13 G. Gruenı, K. Wiesener. A. Kaısheva, S. Gamburtsev and I. Iliev, Elektrokhımiya, 19 (1983) 1571. 
$14 \mathrm{~K}$. Wiesener, Elektrokhimiya. 18 (1982) 758

15 J A.R. van Veen and H.A. Colın, Ber. Bunsenges. Phys. Chem., 85 (1981) 700.

16 D.M. Dražić, Z.V. Ledınskı and S.K. Zecević, J. Appl. Electrochem.. 13 (1983) 337.

17 O. Ikeda. H. Fukuda and H. Tamura, J. Chem. Soc., Chem Commun., (1984) 567.

18 H.P Dhar, R. Darby, V.Y. Young and R.E. White, Electrochım. Acta, 30 (1985) 423.

19 S. Gamburtsev, G. Gruenig, A. Karsheva, I. Iliev and K. Wiesener, Elektrokhimiya, 20 (1984) 500.

20 G. Grueng, Thesis, Dresden, 1983.

21 A. van der Putten, W. Visscher and E. Barendrecht, J. Electroanal. Chem., 195 (1985) 63.

22 A. van der Putten, A. Elzing, W. Visscher and E. Barendrecht, to be published.

23 A Mongilardi-Matıvet. These, Unıversıté de Haute-Alsace, 1981. 